\title{
$\$$

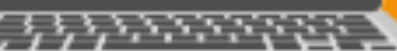 \\ MUDANÇAS NA AVALIAÇÃO DA EAD NO ENSINO SUPERIOR BRASILEIRO DE 2016 A 2019: FLEXIBILIZAÇÃO, (DES)REGULAMENTAÇÃO E AUTORREGULAÇÃO
}

\author{
Aline Fagner de Carvalho e Costa - UFG \\ alinefagner@hotmail.com' \\ João Ferreira de Oliveira - UFG \\ joao.jferreira@gmail.com ${ }^{2}$ \\ Daniela Fernandes Gomes - IFNMG \\ daniela.fernandes@ifnmg.edu.br ${ }^{3}$
}

Eixo 1 - Política, gestão e financiamento da educação a distância

\begin{abstract}
RESUMO: As mudanças legais implementadas na avaliação da educação superior, especialmente no período de 2016 a 2019, indicam maior simplificação, agilização, flexibilização e (des) regulamentação da educação superior, bem como concessão de maior autonomia às Instituições de Ensino Superior (IES) privadas na ampliação de vagas e oferta de cursos. Destacam-se as alterações na Educação a Distância aplicadas a este nível de ensino. O estudo mostrou que as alterações buscam diminuir e flexibilizar os mecanismos de controle da qualidade da educação superior por parte do governo federal, reduzindo o papel regulador e avaliador do Estado. Aponta ainda para a criação de um sistema de autorregulação das IES que atuam no mercado da educação superior.
\end{abstract}

Palavras-chave: Educação Superior. Regulação. Avaliação e Supervisão.

1 Cientista social, doutora em Educação pela Universidade Federal de Goiás (UFG). ORCID: https://orcid.org/0000-0002-6576-7486.

${ }^{2}$ Professor Titular da UFG. Doutor e pós-doutor em Educação pela Universidade de São Paulo (USP). Bolsista produtividade do CNPq. ORCID: https://orcid.org/0000-0002-4135-6340.

${ }^{3}$ Técnica em Assuntos Educacionais do Instituto Federal do Norte de Minas Gerais (IFNMG). Doutoranda em Educação pela UFG. Bolsista do Programa de Bolsas para Qualificação de Servidores do IFNMG. Currículo lattes: http://lattes.cnpq.br/9478463826071478.

III SEMINÁRIO DE EDUCAÇÃO A DISTÂNCIA

Diálogos sobre EaD e uso das TDIC na educação: regulamentação em tempos recentes 3 a 6 de novembro de 2020 - Brasília/DF - Online 


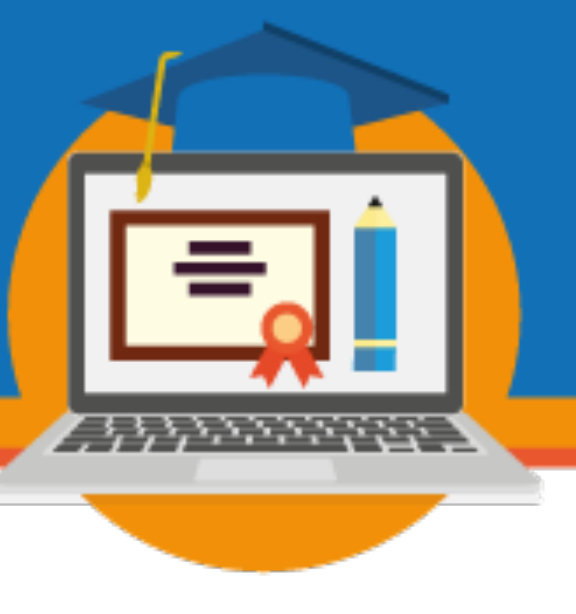

\section{Introdução}

O Sistema Nacional de Avaliação da Educação Superior (Sinaes), criado pela Lei ${ }^{\circ}$ 10.861, de 14 de abril de 2004, perpassou diferentes governos e, apesar de ainda vigorar a sua lei de criação, foi sendo transformado em um sistema de avaliação diferente do que foi pensado em suas origens, sobretudo após a criação, em 2008, do Conceito Preliminar de Curso (CPC) e do Índice Geral de Cursos (IGC). Com uma diversidade de processos e de agentes envolvidos, os mecanismos do Sinaes acabam por caracterizá-lo como um sistema complexo e multifacetado, que busca articular a avaliação da educação superior aos seus procedimentos de regulação e supervisão. Como consequência dessa multiplicidade de fatores, seja por falta de condições materiais para uma implementação mais efetiva ou por transformações na sua concepção, a legislação foi sofrendo sucessivas mudanças para que a política de avaliação fosse sendo transformada no que se apresenta no contexto atual.

Nessa direção, as ações de regulação, que utilizam como base os procedimentos de supervisão e avaliação, foram sendo reformuladas, sobretudo considerando as diferentes concepções, políticas e ações dos governos federais. De modo geral, quando se analisa a regulação e a regulamentação produzida nesses períodos observam-se três momentos marcantes. O primeiro, especialmente no governo Lula da Silva, de maior centralização da regulação e regulamentação na esfera federal, com ênfase em critérios e processos de controle da qualidade e com maior atuação nos processos de supervisão e avaliação, contrapondo-se, em grande parte, ao modelo de avaliação do governo anterior. O segundo, especialmente a partir do final do governo de Dilma Rousseff, que se caracteriza, por um lado, por uma maior tensão entre definição e implementação de padrões de controle da qualidade pelo Estado e, por outro, por ações que visavam instituir maior flexibilização e facilitação nos procedimentos de expansão, sobretudo das IES privadas e da Educação a Distância (EAD). O terceiro momento, que se inicia mais fortemente no governo de Michel Temer e se intensifica no governo de Jair Bolsonaro, amplia os mecanismos de flexibilização, de (des)regulamentação e mesmo de autorregulação das IES privadas a partir da adoção de critérios mais flexíveis e facilitadores da 


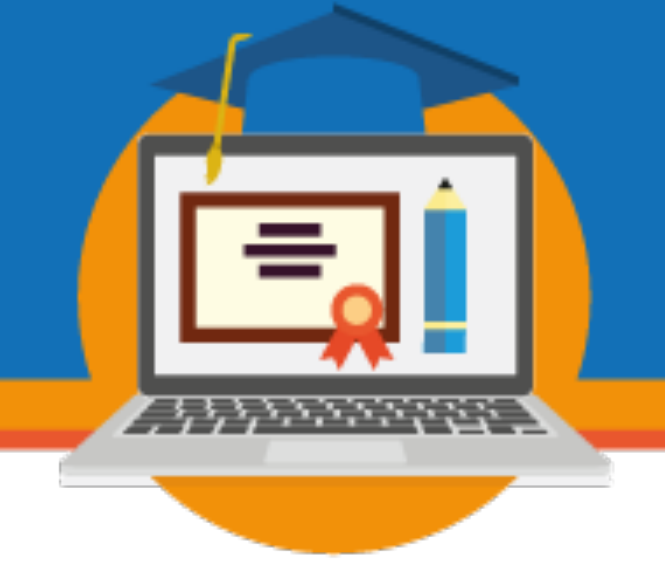

expansão de cursos e vagas; esse último momento aponta para a criação de um sistema de autorregulação das IES que atuam no mercado da educação superior, reduzindo a ação do governo federal nos processos de regulação e supervisão.

Assim, com o objetivo de acompanhar e discutir o movimento das políticas de avaliação, regulação e supervisão da educação superior, assim como, de problematizar o que se anuncia e já se materializa no campo da educação superior no Brasil, com destaque à EAD, busca-se, neste artigo, apresentar elementos fundamentais das principais mudanças legais ocorridas nos últimos anos, sobretudo a partir do governo de Michel Temer, de modo a explicitar as alterações legais efetivadas e que objetivam uma maior flexibilização e (des)regulamentação da educação superior, tendo em vista uma menor presença e atuação do Estado, em favor de uma autorregulação do setor privado; a autonomia crescente na expansão da EAD e nessa direção, a autorregulação, por meio da concorrência entre as IES privadas, é que passaria a "zelar pela qualidade do ensino".

\section{As políticas de avaliação da educação superior rumo à flexibilização e (des)regulamentação}

Historicamente, as mudanças na base legal das políticas públicas tendem a acompanhar a lógica econômica e política vigentes, considerando os elementos que caracterizam cada governo (DIAS SOBRINHO, 2010; VERHINE, 2015; BARREYRO, 2008). Na atualidade, a lógica neoliberal vem direcionando as políticas e ações governamentais no sentido de implementar a chamada sociedade de livre mercado e a redução de direitos sociais constitucionais, como é o caso da educação. A educação vem sendo concebida como mercadoria, sendo atribuída a ela a dinâmica do mercado, que compreende, além de diferentes formas de gerencialismo, mercadorização, terceirização e privatização, a apropriação de uma lógica do privado na perspectiva de uma concorrência interna, que favorece a individualização, distinção e premiação por resultados (DOURADO; OLIVEIRA, 2018, p. 42).

Desde os mandatos de FHC, as políticas de educação superior do Brasil caminharam na 
direção da dissociabilidade entre ensino e pesquisa especialmente por meio da diversificação e diferenciação das IES, dos cursos e dos processos seletivos, articulando flexibilidade, competitividade e avaliação, com o objetivo de tornar as IES mais eficientes e eficazes no desempenho de suas funções (OLIVEIRA, 2000). A partir da segunda metade dos anos 1990, observou-se a adoção de processos de "diversificação das instituições, dos programas, dos cursos, das finalidades e das vocações institucionais" que, aliados ao "processo de expansão, regionalização e atendimento ao meio econômico e social onde estão inseridas", resultou em alterações nas políticas de financiamento e avaliação, nos padrões de qualidade, formação, pesquisa, pós-graduação, gestão e organização das IES (FERREIRA; OLIVEIRA, 2016, p. 8).

No contexto da reforma do Estado, seguiam certas diretrizes que tinham como propósito a caracterização da educação como serviço público não estatal; a redução do financiamento público das IES federais; a modificação do papel do Estado, de financiador para avaliador; a ampliação das parcerias público-privadas; o crescimento dos processos de mercantilização e privatização; o incentivo às fontes alternativas de financiamento; a diferenciação e a competitividade entre instituições; a expansão a baixo custo; a ampliação do ensino a distância; a implementação de sistemas de avaliação por desempenho; as mudanças no trabalho docente centradas na produtividade; e a formação para atender às demandas do mercado de trabalho (CARVALHO; FERREIRA, 2016).

A partir de 2004, com a criação do Sinaes, parece haver dois períodos peculiares. O primeiro entre 2004 e 2015 quando, nos governos Lula e Dilma, foi criado e instituído o Sinaes e os indicadores de qualidade. Neste período, o Estado apresenta-se como o principal agente na definição de critérios, dimensões e elementos de qualidade, embora se buscasse também no âmbito do Sinaes uma avaliação que favorecesse o desenvolvimento das instituições, públicas e privadas, sobretudo por meio da autoavaliação.

O segundo período, iniciado nos governos de Michel Temer (2016-2018) e Jair Bolsonaro, a partir de 2019, ainda mantem o Sinaes, entretanto, com características que remetem a uma perspectiva de flexibilização e (des)regulamentação da educação superior, tendo como horizonte uma tendência a autorregulação do sistema. Em especial a partir do 
governo Michel Temer, foram observadas mudanças substanciais da educação superior, que provocaram uma flexibilização de normas, tendo como pontos principais: simplificação de processos, diminuição de exigências, concessão de mais autonomia para aspectos específicos, mudanças em processos e atribuições de órgãos (quase sempre para reduzir burocracia) e novidades nos indicadores, quase sempre no sentido de torná-los mais subjetivos, dentre outros.

\section{Sucessivas mudanças para a avaliação da educação superior e a EAD}

Nos documentos legais e normativos levantados, mais diretamente relacionados à avaliação da educação superior, entre 2016 e 2019, tem-se como assuntos abordados: instrumentos e indicadores de qualidade; Sinaes; regulação; supervisão; avaliação; avaliação especial; diretrizes, regulação e avaliação da EAD; Exame Nacional de Desempenho dos Estudantes (Enade); prazos dos atos autorizativos; alteração no número de vagas; Comissão Técnica de Acompanhamento da Avaliação (CTAA); Comissão Nacional de Avaliação da Educação Superior (Conaes); cadastro de concluintes; expedição e registro de diplomas, inclusive digital; ampliação em alguns casos do percentual da oferta de EAD; apuração de irregularidade no Enade; e outras flexibilizações com base em indicadores de qualidade.

As alterações legais e normativas em 2016 que guardam relação com o Sinaes, nos momentos finais do governo Dilma foi sucessivamente alterada ou revogada, no período interino de Michel Temer. Sucessivos documentos que versavam sobre indicadores de qualidade foram revogados, resultando, em 2019, em comissão de assessoramento para reformulação dos mecanismos e instrumentos de regulação, avaliação e supervisão. Contudo, a Comissão de Assessoramento foi extinta antes de ter tempo para atuar, pela Portaria n. $984 / 2019$.

As mudanças de processos e de atribuição de órgãos e a concessão de autonomia para as IES se autorregularem figuram entre os pontos de alteração. A mudança na estrutura institucional e burocrática constituída no âmbito do poder público implica em alterações no modus operandi da educação superior, bem como em sua concepção e propósito. Destacamos 


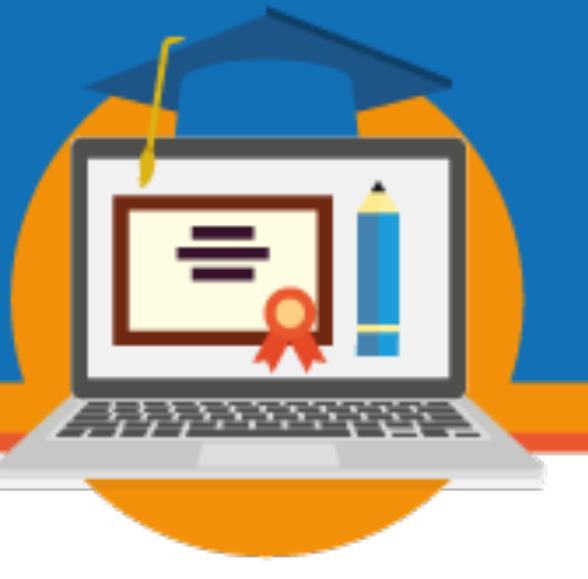

como submetidos à referida dinâmica: CTAA, Conaes e Secretaria de Regulação e Supervisão da Educação Superior (Seres); o Banco de Avaliadores do Sinaes (Basis); e Projeto de Avaliação Especial (AE).

Tais modificações nos sugerem, além de um enfraquecimento da CTAA em suas atribuições, o abrandamento de penalidade aos integrantes do BASIs. A Portaria Normativa n. 840/2018, que revogou a Portaria Normativa n. 19/2017, facilita e simplifica os critérios para composição da comissão de avaliação in loco de IES e cursos a distância. Passa a não exigir experiência em EAD para avaliadores in loco nos processos de avaliação institucional e a não exigir formação na área de Tecnologia da Informação e Comunicação, para o caso de avaliação de cursos a distância.

O Decreto n. 9.235, de 2017, normativa legal mais importante que marca o ciclo de regulamentação/regulação pós-afastamento de Dilma, se refere a: atos de regulação da educação superior delegados ao Secretário da Seres/MEC, por prazo indeterminado, e competência para credenciamento provisório; concessão de prerrogativa para faculdades com Conceito Institucional (CI) máximo registrarem seus diplomas; e extensão de prerrogativas de autonomia para campus fora de sede de universidades. As mudanças indicam concessão de autonomia às IES de excelência. Entretanto, resta problematizar de que forma os sentidos de excelência e de autonomia se aplicam para as IES públicas e privadas.

\section{Flexibilização e concessão de autonomia: (des)regulamentação da educação superior}

A flexibilização e a concessão de autonomia estão entre as ações previstas na base legal, entre 2016 e 2019, que possuem relação com o Sinaes e para EAD. Na Portaria Normativa n.23, de 21/2017, já eram dispensadas a avaliação externa in loco para autorização de cursos, após análise documental, desde que atendidos critérios relacionados à qualidade. $\mathrm{Na}$ Portaria Normativa n. 20, de 21/2017, flexibiliza ao permitir conceito 2,8 (dois vírgula oito) em um dos eixos, desde que os outros sejam iguais ou superiores a três. Entretanto, o artigo $2^{\circ}$ condiciona

\section{SEMINÁRIO DE EDUCAÇÃO A DISTÂNCIA}


os processos de credenciamento e recredenciamento às avaliações in loco.

Quanto à avaliação externa in loco de IES e de cursos na Nota Técnica $n$. 16/2017/CGACGIES/DAES/Inep, as mudanças sinalizam critérios mais qualitativos e menos quantitativos. Estabelece também a separação entre atos de entrada (credenciamento e autorização) e atos de permanência (recredenciamento e transformação de organização acadêmica, reconhecimento e renovação de reconhecimento); e a unificação de instrumentos das modalidades presencial e a distância. Por outro lado, observa-se maior relevância dos órgãos colegiados como Comissão Própria de Avaliação (CPA) e Núcleo Docente Estruturante (NDE). Outras novidades referem-se à Equipe Multidisciplinar para a modalidade a distância.

No caso da educação a distância, o Decreto n. 9.235/2017 equiparou os processos de regulação, supervisão e avaliação de cursos desta modalidade à presencial, bem como congregou, de forma clara, a pós-graduação lato sensu e a EAD ao Sinaes. Na sequência, a Portaria Normativa n. 23/2017 determinou alguns atos que independem de autorização do MEC, como a criação e extinção de polo EAD e a vinculação e desvinculação de cursos EAD a polos. Além disso, regulamentaram os requisitos para a concessão de credenciamento prévio e autorização de curso provisório, EAD e presencial. Em agosto de 2018 foi alterada pela Portaria Normativa n. 742/2018 para, dentre outras questões, deixar claro o limite máximo de carga horária presencial em cursos $\mathrm{EAD}$, que deve ser de até $30 \%$ da carga horária total do curso, ressalvadas a carga horária referente ao estágio obrigatório e as especificidades previstas nas Diretrizes Curriculares Nacionais do Curso. Pouco antes, o Decreto n. 9.057, de 25 de maio de 2017, que regulamentou artigo da LDB/1996 referente à EAD já era omisso sobre o assunto, não prevendo momentos presenciais obrigatórios em cursos a distância.

Ainda em 2017, a Portaria Normativa n. 11, normatizou o credenciamento e a oferta de cursos a distância, inclusive para pós-graduação lato sensu. Em seu texto, diferentes itens apontam uma flexibilização ou diminuição de rigor na avaliação e regulação da educação superior a distância, uma vez que: permitiu o credenciamento de IES para oferta de cursos superiores a distância sem o credenciamento para oferta de cursos presenciais; determinou que as avaliações in loco nos processos de EAD serão concentradas no endereço sede da IES e, no 
que se refere aos polos de EAD previstos no Plano de Desenvolvimento Institucional (PDI) e nos Projetos Pedagógicos dos Cursos e os ambientes profissionais utilizados para estágio supervisionado e atividades presenciais, estes serão verificados por meio documental ou com a utilização de recursos tecnológicos disponibilizados pelas IES; consentiu a oferta de cursos superiores a distância sem previsão de atividades presenciais, desde que autorizado previamente pela Seres/MEC após avaliação in loco no endereço sede, o que configura oferta de cursos totalmente a distância; flexibilizou o Decreto n. 9.057/2017 ao estipular que é possível ofertar cursos superiores presenciais em instalações de polo EAD desde que estas sejam, também, unidades acadêmicas presenciais devidamente credenciadas.

A tendência à flexibilização é observada em diferentes oportunidades, ao permitir: o remanejamento de vagas autorizadas de um curso $\mathrm{EaD}$ entre polos; parcerias entre IES credenciada para educação a distância e outras pessoas jurídicas, preferencialmente, e não necessariamente em instalações da instituição de ensino; que as atividades presenciais dos cursos de pós-graduação lato sensu a distância poderão ser realizadas em locais distintos da sede ou dos polos de EaD. Por fim, este documento regulamentou a possibilidade de utilização de ambientes profissionais como forma de organização de atividades presencias ou estágio supervisionado de cursos a distância, desde que a parceria seja formalizada em documento próprio.

Sobre a oferta de disciplinas a distância em cursos de graduação presencial, a Portaria n. 1.428 , de 28 de dezembro de 2018, revogou a Portaria n. 1.134, de 10 de outubro de 2016, para estabelecer importante modificação ao aumentar de $20 \%$ para $40 \%$, desde que cumpridos alguns requisitos referentes aos processos de regulação e supervisão. Fato que valoriza a EAD e permite tornar mais hibrida a oferta dos cursos presenciais, o que altera a organização curricular das IES, bem como a situação do corpo docente. Em 2019, nova mudança ocorreu quando a Portaria n. 2.117, revogou a Portaria n. 1.428/2018 para regulamentar a oferta de carga horária na modalidade EAD em cursos de graduação presenciais, mantendo o limite dos $40 \%$.

Ressalta-se que, no momento da avaliação in loco, apesar dos instrumentos utilizados serem únicos para cursos presenciais e a distância, aqueles que possuem carga horária parcial 


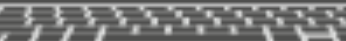

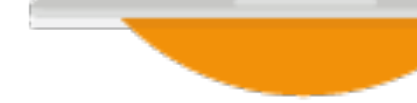

ou completa nesta modalidade têm que comprovar a presença de alguns requisitos exclusivos para esta modalidade, como as tecnologias de informação e comunicação, os tutores e outros. Como situações que resultam em flexibilização e concessão de autonomia, pode-se mencionar, ainda, a expedição e o registro de diplomas por faculdades; o aumento e a redução de vagas em cursos de IES; e a oferta de cursos técnicos de nível médio por IES privadas. Algumas das questões alteradas pela Portaria n. 741/2018 referem-se a: explicitação de que o indicador de qualidade será utilizado apenas de forma subsidiária nos processos de autorização quando o CI for inexistente ou satisfatório obtido há mais de cinco anos, com exceção de alguns cursos presenciais e dos cursos na modalidade EaD.

Merece atenção o que foi implementado nos procedimentos de avaliação externa in loco, relativizada por uma mudança no papel da comissão de avaliadores uma vez que seu trabalho passou a se fundamentar mais em aspectos qualitativos, com uma lógica avaliativa mais subjetiva e uma ênfase em evidências (atas, relatórios, comprovantes) construídos pela IES. Ademais, o papel dos órgãos colegiados da IES assume relevo uma vez que estes são responsáveis por construir os relatórios, dessa forma, a própria IES, por meio de seus colegiados, atribui a sua qualidade. Isso configura, até certo ponto, uma concessão de prerrogativa aos órgãos colegiados da IES para definirem o seu padrão de qualidade.

\section{Considerações Finais}

Ao logo desse estudo buscou-se analisar as mudanças na base legal que trata da avaliação, regulação e supervisão das IES e dos cursos de educação superior, sobretudo no período de 2016 a 2019. Na esteira das mudanças, o modelo de avaliação do Sinaes, na forma como foi aprovado em 2004, já perdeu muito da sua identidade e de seu propósito devido à lógica, às políticas e as ações semeiam profundas dinâmicas neste campo. Foram várias as revogações e alterações na base legal em pouquíssimo tempo, como se examinou.

O governo federal desde o impeachment vem eliminando mecanismos e critérios mais objetivos que estabeleciam padrões de qualidade, bem como procedimentos que haviam sido 
criados com a presença de agentes públicos no processo de supervisão de IES e cursos. Verificou-se que há uma crescente ampliação dos processos e mecanismos de flexibilização e de (des)regulamentação por meio da adoção de critérios mais flexíveis e facilitadores da expansão de cursos e vagas sobretudo de IES privadas, especialmente no tocante a EAD. Mais recentemente, no governo de Jair Bolsonaro, já se fala na criação de um sistema de autorregulação das IES que atuam no mercado da educação superior, entregando, portanto, a regulação ao próprio mercado, o que significa que a aferição da qualidade da educação superior não seria uma atribuição do Estado, mas realizada pela própria concorrência entre as IES que atuam no setor.

Percebe-se como tendência em curso para essas políticas: o aumento da subjetividade na avaliação externa in loco, inclusive sua dispensa; a flexibilização na valoração dos conceitos vinculados aos atos autorizativos; o favorecimento e a facilitação que a base legal promove para a oferta de $\mathrm{EAD}$, inclusive com a possibilidade de oferta de cursos totalmente a distância, com a concessão de autonomia para criação de polos, a flexibilização de currículos e a permissão de ofertar $40 \%$ da carga horária de curso presencial na forma EAD; a flexibilização do que antes era regra, no que se refere à titulação docente, favorecendo IES com professores menos titulados; a diminuição da rigidez dos critérios para transformação de organização acadêmica; a concessão de autonomia para o registro de diplomas, assim como para aditamento de vagas dos cursos de graduação, com base em conceitos satisfatórios.

A "nova regulação" em curso também tem alterado as finalidades, as atribuições e a atuação dos órgãos envolvidos no sistema de avaliação, a exemplo das realizadas pela Seres/MEC, Inep, CNE, Conaes, CTAA, etc. Com efeito, a partir do governo de Michel Temer, observa-se maior desconstrução da política do Sinaes que ocorre como forma de (des)regulamentar a educação superior. Mudanças no sentido de facilitar e favorecer a expansão privada, sobretudo daquelas que operam por meio da financeirização, o que resulta em alterações nas finalidades, na organização, nas condições de oferta e no funcionamento das IES.

O cenário atual, de crise econômica e de reformas neoliberais que reduzem os gastos públicos e o papel do Estado nas políticas sociais, assim como, as mudanças em curso, 


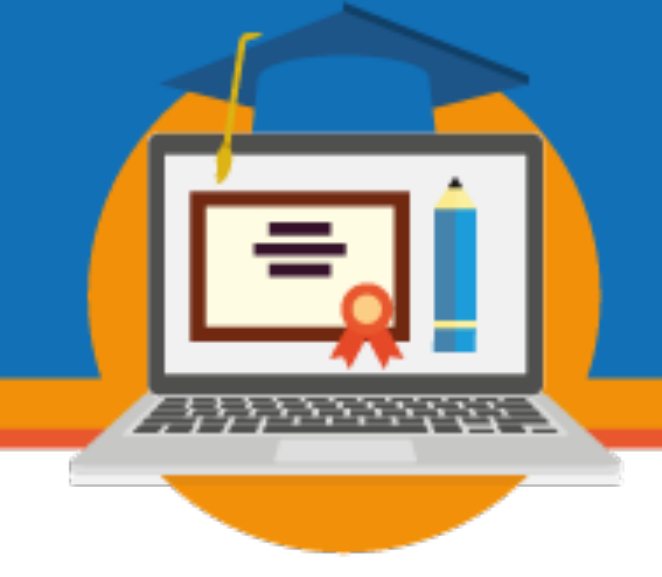

favorecem a ação dos grandes grupos econômicos e financeiros em termos da expansão da educação superior, especialmente na modalidade a distância. Além disso, o projeto do atual governo, concentrado na liberdade econômica e de mercado e na diminuição do Estado como agente normativo e regulador, tem resultado também na ausência de projetos que fortaleçam as IES públicas e seus compromissos sociais.

A crença no fundamentalismo de mercado em que a produção e a comercialização devem ser entregues aos próprios agentes econômicos interessados em investir e realizar a autovalorização do capital parece estar guiando a política de educação superior, sobretudo na avaliação, regulação e supervisão desse sistema. Neste contexto, a dimensão pública tem ficado em segundo plano, assim como a perspectiva da educação superior como bem público e a produção do conhecimento como um bem social.

\section{Referências}

BARREYRO, G. B. De exames, rankings e mídia. Campinas, Sorocaba, SP, v.13, n.3, p.863868, nov. 2008. Disponível em: http://www.scielo.br/scielo.php?script=sci arttext\&pid=S141440772008000300017\&lng=en\&nrm=iso

CARVALHO, Renata Ramos da Silva; FERREIRA, Suely. Universidades Federais: desafios da expansão e da democratização do acesso ao ensino superior. In: FERREIRA, Suely; OLIVEIRA, João Ferreira de (Orgs.). Universidades Públicas: mudanças, tensões e perspectivas. Campinas: Mercado das Letras, 2016.

CUNHA, Luiz Antônio. Ensino superior e universidade no Brasil. In: 500 anos de educação no Brasil. Belo Horizonte: Autêntica, 2000. p.151-204.

DIAS SOBRINHO, José. Avaliação e transformações da educação superior brasileira (19952009): do provão ao Sinaes. Avaliação. Campinas, Sorocaba, SP, v.15, n.1, p.195-224, mar. 2010 .

DOURADO, Luiz Fernandes; OLIVEIRA, João Ferreira de. Base Nacional Comum Curricular (BNCC) e os impactos nas políticas de regulação e avaliação da educação superior. In: 


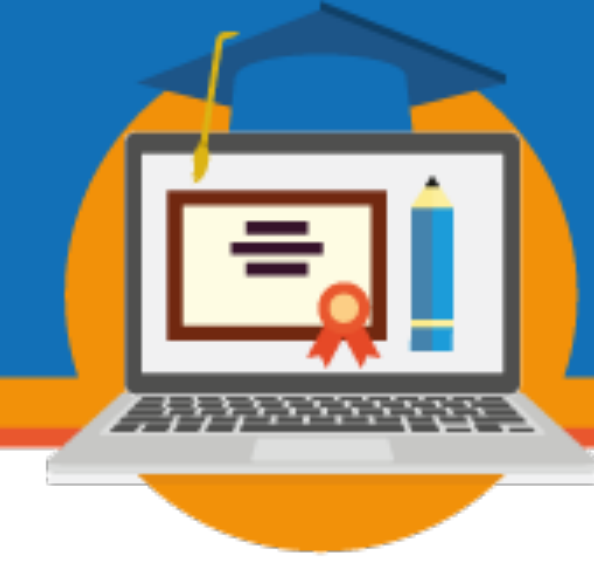

AGUIAR, Márcia Angela; DOURADO, Luiz Fernandes (Orgs.). A BNCC na contramão do PNE 2014-2024: avaliação e perspectivas [Livro Eletrônico]. Recife: Anpae, 2018.

FERREIRA, Suely; OLIVEIRA, João Ferreira de. Universidades Públicas: mudanças, tensões e perspectivas. Campinas: Mercado das Letras, 2016.

OLIVEIRA, João Ferreira de. A reestruturação da educação superior no Brasil e o processo de metamorfose das Universidades Federais: o caso da Universidade Federal de Goiás (UFG). 2000. 210 f. Tese (Doutorado em Educação) - Programa de Pós-Graduação em Educação, Universidade de São Paulo, São Paulo.

VERHINE, Robert E. Avaliação e regulação da educação superior: uma análise a partir dos primeiros 10 anos do SINAES. Avaliação, Campinas; Sorocaba, SP, v.20, n.3, p.603-619, nov. 2015 . 